\title{
BMJ Open Long-acting somatostatin analogue treatments in autosomal dominant polycystic kidney disease and polycystic liver disease: a systematic review and meta-analysis
}

Joshua Griffiths (1) , Mark T Mills, Albert CM Ong (C)

To cite: Griffiths J, Mills MT, Ong ACM. Long-acting somatostatin analogue treatments in autosomal dominant polycystic kidney disease and polycystic liver disease: a systematic review and meta-analysis. BMJ Open 2020;10:e032620. doi:10.1136/ bmjopen-2019-032620

- Prepublication history and additional material for this paper are available online. To view these files, please visit the journal online (http://dx.doi. org/10.1136/bmjopen-2019032620).

Received 27 June 2019 Revised 27 November 2019 Accepted 13 December 2019

Q Check for updates

(c) Author(s) (or their employer(s)) 2020. Re-use permitted under CC BY-NC. No commercial re-use. See rights and permissions. Published by BMJ.

Kidney Genetics Group, Academic Unit of Nephrology, Department of Infection, Immunity and Cardiovascular Disease, The University of Sheffield, Sheffield, UK

Correspondence to Dr Joshua Griffiths; jgriffiths1@doctors.org.uk

\section{ABSTRACT}

Objectives A number of randomised control trials (RCTs) investigating the effects of long-acting somatostatin analogues in autosomal dominant polycystic kidney disease (ADPKD) and polycystic liver disease (PLD) have been recently reported. We sought to evaluate all available RCTs investigating the efficacy of somatostatin analogues treatment in ADPKD and PLD.

Data sources Electronic databases; Pubmed,

Clincaltrials.gov and Cochrane Central Register of Controlled Trials

Eligibility criteria for selecting studies RCTs and randomised cross-over trials comparing the effects of somatostatin analogue treatment with controls in patients with ADPKD or PLD.

Data extraction and synthesis Data extraction and bias assessments were performed by two independent reviewers between January and May 2019. Outcomes assessed included estimated glomerular filtration rate (eGFR), total kidney volume (TKV), total liver volume (TLV), progression to end stage renal failure (ESRF) and adverse effects. Data were pooled using a random-effects model and reported as relative risk or mean difference with $95 \%$ Cls.

Results Meta-analysis was performed of six RCTs or randomised cross-over trials and three secondary analyses. A total of 592 patients were included. Compared with controls, somatostatin analogue treatment significantly reduced TLV (mean difference $-0.15 \mathrm{~L}$, $95 \% \mathrm{Cl}-0.26$ to $-0.03, \mathrm{p}=0.01)$. There was no significant effect on TKV (mean difference $-0.19 \mathrm{~L}, 95 \% \mathrm{Cl}-0.50$ to $0.12, p=0.23$ ) or eGFR (mean difference $0.27 \mathrm{~mL}$ / $\min / 1.73 \mathrm{~m}^{2}, 95 \% \mathrm{Cl}-2.03$ to $2.57, \mathrm{p}=0.82$ ). There was no effect on progression to ESRF. Somatostatin analogues were associated with known adverse effects such as gastrointestinal symptoms.

Conclusions The available RCT data show improvement in TLV with somatostatin analogue treatment. There was no benefit to TKV or eGFR in patients with ADPKD, while being associated with various side effects. Further studies are needed to assess potential benefit in reducing cyst burden in patients with PLD.
Strengths and limitations of this study

- This is the only systematic review and meta-analysis assessing the role of long-acting somatostatin analogues in both autosomal polycystic kidney disease and polycystic liver disease to date.

- Only randomised control and randomised cross-over trials were included.

- Variation in baseline total kidney volume in multiple trials may confound results.

- There are a small number of trials available, largely with small patient numbers.

- There was no consensus on somatostatin analogue formulation with variation between studies.

\section{INTRODUCTION}

Autosomal dominant polycystic kidney disease (ADPKD) is the most prevalent monogenic disease in the world, the single most common inherited kidney disease and the fourth most common cause of end stage renal failure (ESRF). ${ }^{1}$ Prevalence rates for ADPKD vary greatly in different populations and countries, with rates reported between $1: 400$ and $1: 1000^{2}$ although more recent estimates suggest a point prevalence of clinically diagnosed cases of 4:10 000 in Europe. ${ }^{3}$

The cardinal feature of ADPKD is the development of large numbers of fluid-filled cysts that disrupt normal kidney structure, leading to the gradual loss of renal function. The disease is usually progressive and results in the need for dialysis or renal transplantation. ADPKD accounts for approximately $5 \%-10 \%$ of all patients with ESRF at an estimated cost of 1.6 billion euro per year across Europe. ${ }^{3}$ Alongside renal morbidity, ADPKD is associated with several common extrarenal manifestations including polycystic liver disease (PLD) and intracranial aneurysms 
which may further worsen individual patient's disease burden. ${ }^{4}$

ADPKD most commonly results from a germline mutation in either PKD1 or PKD2 while a number of patients with ADPKD who are negative for either gene carry GANAB (glucosidase II alpha subunit) mutations. ${ }^{5}$ PKD1 mutations are present in approximately $80 \%$ of ADPKD patients and are associated with an earlier onset of ESRF compared with PKD2 mutations. ${ }^{6}$ The growth and expansion of cysts leads to the destruction of normal kidney structure and results eventually in the permanent loss of function and ESRF. ${ }^{3}$ PLD is the most common extrarenal manifestation of ADPKD and has been reported to occur in approximately $83 \%$ of patients. More rarely, PLD can occur in isolation from ADPKD, due to mutations in other genes such as protein kinase C substrate $80 \mathrm{~K}-\mathrm{H}$ (PRKCSH), SEC63, SEC61B, alpha-1,3-glucosyltransferase $(A L G 8)$ and low-density lipoprotein receptor-related protein 5 (LRP5), leading to autosomal dominant polycystic liver disease (ADPLD). ${ }^{7-10}$ There is however increasing recognition of a phenotypic overlap between patients with ADPKD and ADPLD with a spectrum of disease severity. ${ }^{11} 12$

At present, there is no cure for ADPKD, and only one drug, tolvaptan, has been approved to slow renal disease progression. ${ }^{13}$ However, tolvaptan has been associated with a variety of poorly tolerated adverse effects especially profound aquaresis and rare cases of hepatotoxicity making it unsuitable or intolerable in many patients. ${ }^{14}$ Therefore there is a significant need for alternate or adjunctive treatments in the management of ADPKD and PLD.

Cyst growth in ADPKD and PLD has been linked to the activation of several different signalling pathways, particularly several involving cyclic adenosine monophosphate (cAMP). Increased levels of cAMP have been associated with accelerated cyst development, cell proliferation and disease progression; thus reducing cAMP levels represents a logical therapeutic aim. ${ }^{15}$ Targeting somatostatin receptors with long-acting somatostatin analogues such as octreotide has been shown to reduce cAMP accumulation and disease progression in experimental models of ADPKD and PLD. ${ }^{16}$ Consequently, the use of somatostatin analogues has been proposed as a potential treatment for ADPKD and ADPLD, with several trials having been recently completed. While there have been two previous individualised meta-analysis' assessing somatostatin analogues in PLD ${ }^{17}{ }^{18}$ no focused systematic review of all trials in ADPKD and PLD has been published to date.

\section{METHODS}

\section{Search strategy}

The search strategy used consisted of electronic database searches using key terms such as ADPKD, somatostatin and PLD. Three online databases were used: Pubmed (with a search filter for clinical trials), Clincaltrials.gov and Cochrane Central Register of Controlled Trials. A summary of search terms used and the strategy is shown in online supplementary table 1. Searching began in January 2019 and was completed on 10 May 2019.

\section{Study selection}

Inclusion criteria were as follows:

1. Randomised control trial (RCT) with appropriate control subjects.

2. Intervention with an appropriate long-acting somatostatin analogue administered monthly at any dose in any formulation.

3. Relevant outcomes to this review (total kidney volume (TKV), total liver volume (TLV), estimated glomerular filtration rate (eGFR), blood pressure (BP), adverse effects, progression to ESRF, mortality and hospital admissions).

4. Patients with a clinical and radiological diagnosis of ADPKD or PLD.

Only adults were included. There were no restrictions on baseline renal function or genetic analysis. Secondary analysis of previous trials was accepted if the trial in question was also included in this review. Only trials available in English were included. Studies with interventions that included another treatment (such as combination with tolvaptan), observational trials and pooled analysis studies were excluded. Patients with liver or kidney transplants were excluded from TKV and eGFR or TLV analysis, respectively. Patients with Chronic Kidney Disease Stage 5 (CKD5) or receiving dialysis were also excluded.

\section{Primary outcomes}

- TKV in ADPKD.

- TLV in PLD.

- eGFR decline in ADPKD.

\section{Secondary outcomes}

- Adverse effects (blood glucose, abdominal pain, diarrhoea, cholelithiasis, cholecystitis and alopecia).

- Discontinuation rates.

- BP.

- Progression to ESRF.

- All-cause mortality

- Hospital admissions.

\section{Quality assessment}

Studies were assessed for bias by two independent reviewers using a standardised bias assessment form developed by Cochrane reviews and available from the Cochrane reviews handbook. ${ }^{19} 20$ The tool assesses publications for various forms of bias, including selection, performance, detection, attrition and reporting and were scored as high, low or unclear risk of bias for each area. Publication bias was assessed using Funnel plots and visual inspection in accordance with the Cochrane reviews handbook. ${ }^{20} \mathrm{We}$ used the PRISMA checklist to confirm that our review was PRISMA compliant. 


\section{Data extraction}

Data extraction was performed by two independent reviewers using a data extraction form developed from a standard electronic form for the purposes of this review. Data extracted included study details, patient population details, relevant outcomes and interventions. In publications where both TLV and TKV were reported, results were separated for patients with PLD and ADPKD which allowed individual meta-analysis of both measurements. Authors were not contacted for missing data.

\section{Statistics}

Statistical analysis was performed using Review Manager V. $5.3^{21}$ with inverse variance used for continuous data and Mantel-Haenszel for dichotomous data. A randomeffects model was used throughout. Effect estimates of individual and pooled trial data were represented by

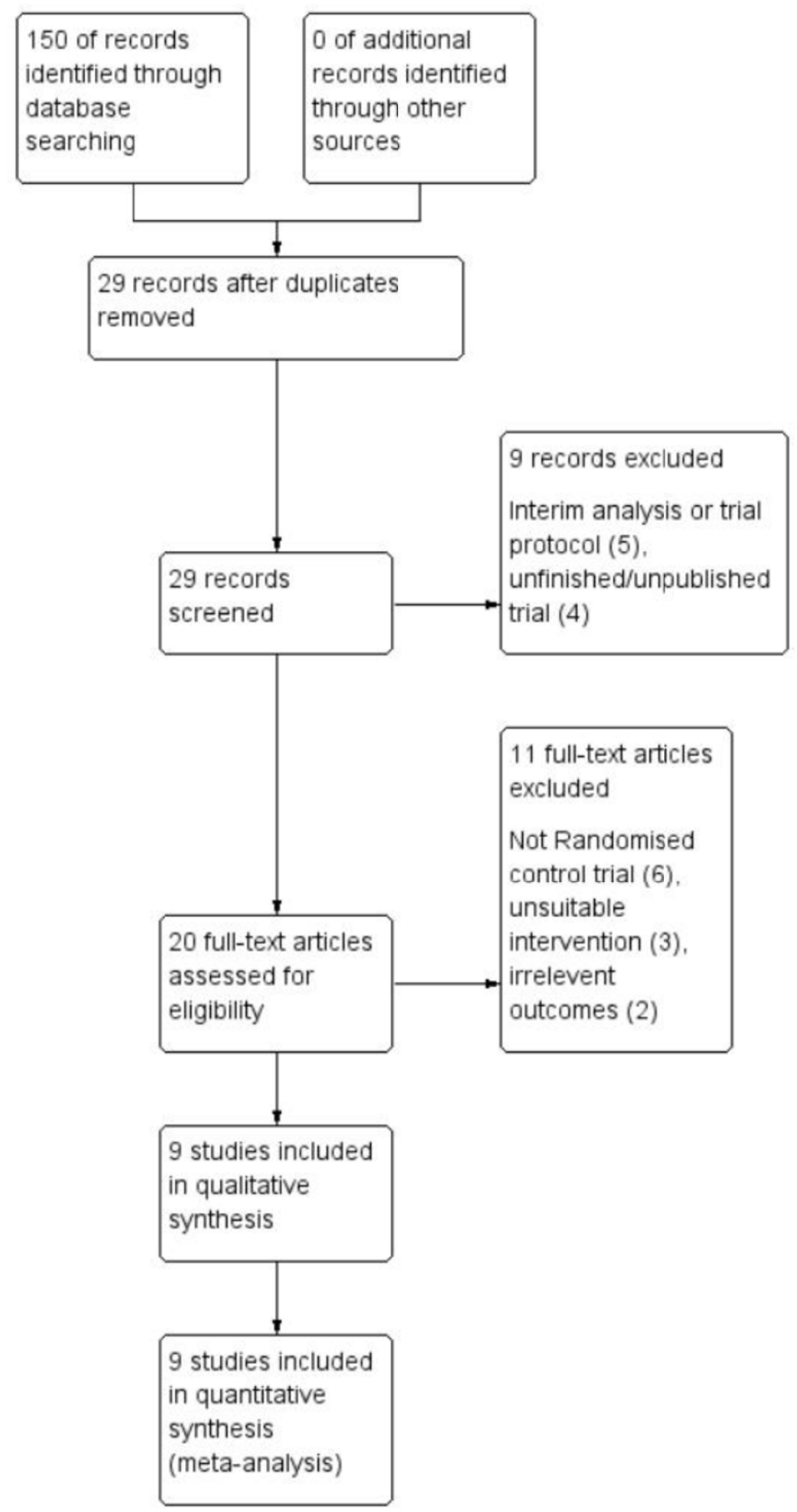

Figure 1 Study flow diagram. mean difference or risk ratios with appropriate $95 \%$ CIs. Standardised mean differences were used for continuous outcomes with different methods of quantification between studies. If no final post-treatment mean value was reported, mean change from baseline was used and the results were analysed together as unstandardised mean differences as detailed in the Cochrane handbook. $^{20}$ Results were demonstrated via Forest plots. P values were two-tailed and a significance value of $<0.05$ was used in all statistical tests. Any missing SD that were required were imputed using published methods in the Cochrane handbook. ${ }^{20}$ Heterogeneity was assessed using $Q$ values and $\mathrm{I}^{2}$ test with scores below 25\% deemed low, $25 \%-50 \%$ medium and $>50 \%$ high heterogeneity. ${ }^{22}$ Metaregression was not performed due to the small number of studies included.

\section{Patient and public involvement}

No patients were involved in the completion of this study.

\section{RESULTS}

The search strategy identified 29 publications that had potential to be included in this review. Of these trials, five were interim analyses of ongoing trials or trial protocols and four were unpublished trials. Another six trials were not RCTs (observational or safety trials), three used unsuitable interventions and two reported irrelevant outcomes. See figure 1 for an overview of the study selection process.

A total of six studies were included consisting of five $\mathrm{RCTs}^{23-27}$ and one randomised crossover trial. ${ }^{28}$ Of these, four included ADPKD patients alone $\mathrm{e}^{25-28}$ and the remaining two included patients with PLD and ADPKD, but provided a subset of data for ADPKD patients when measuring renal function and TKV. ${ }^{23} \mathrm{~A}$ further three publications were included as they were secondary analyses of previous studies, ${ }^{29-31}$ all of which were investigating the change in TLV for a subset of patients with PLD in a post-hoc analysis. Excluding patient numbers from secondary analysis, a total of 592 patients were included.

All included studies recruited both male and female participants who were over the age of 18 and with a clinical and radiological diagnosis of ADPKD (according to the Ravine Criteria in the majority of studies). The most significant variation in inclusion criteria between studies was baseline renal function. These differing criteria and summaries for the included trials and publications are outlined in table 1 .

\section{Bias risk assessment}

Bias assessments are summarised in figure 2. Notable bias was detected in blinding for several studies. In ALADIN 2013 (and Pisani et $a l^{30}$ ), physicians and staff were not blinded to patient allocation groups, and DIPAK-1 (and van Aerts et $a l^{29}$ ) was an open-label study: therefore, both had a high risk of bias for blinding of participants. All studies except Ruggenentti et $a l^{28}$ reported that TKV and TLV measurements were performed by blinded 


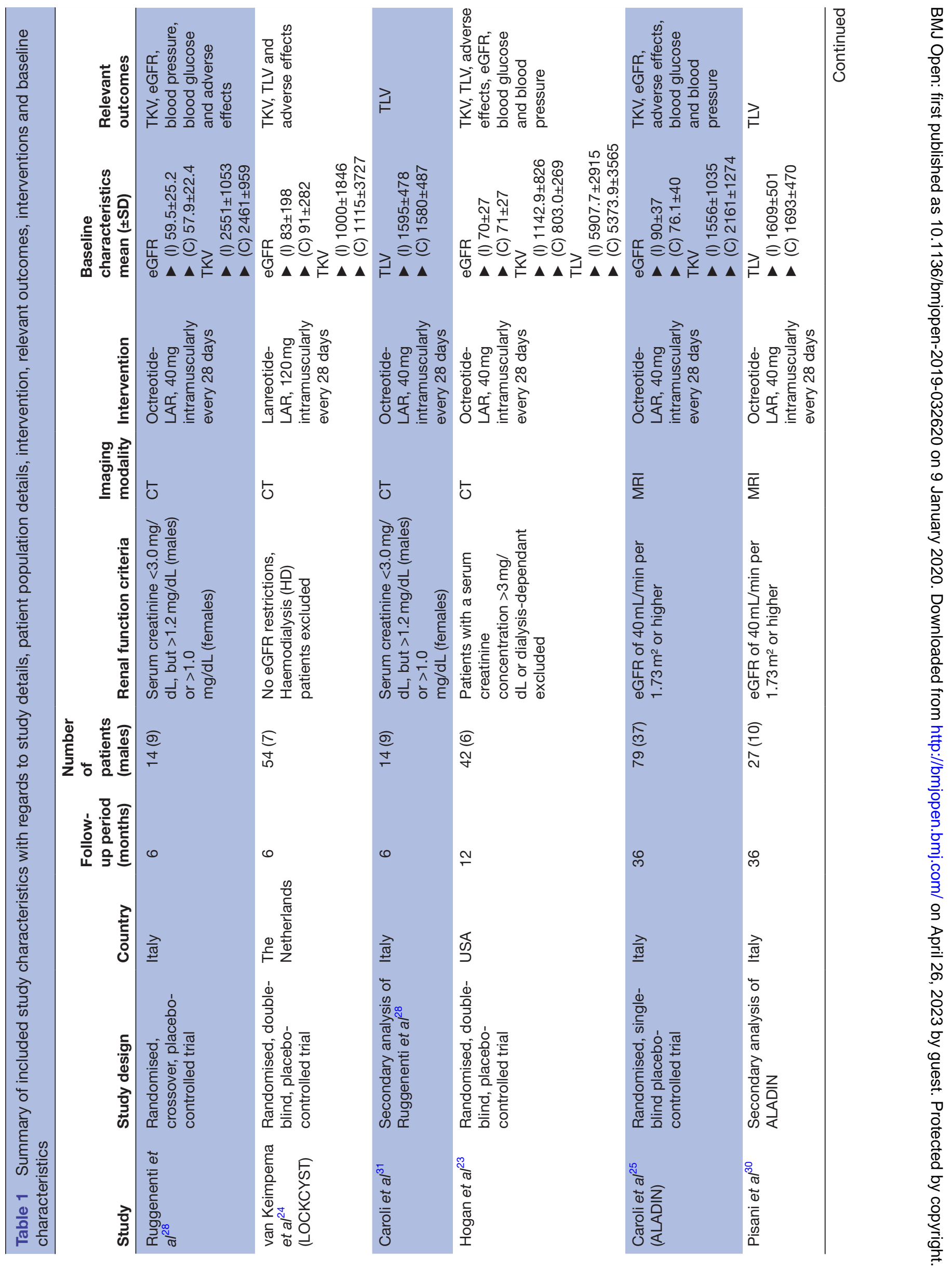




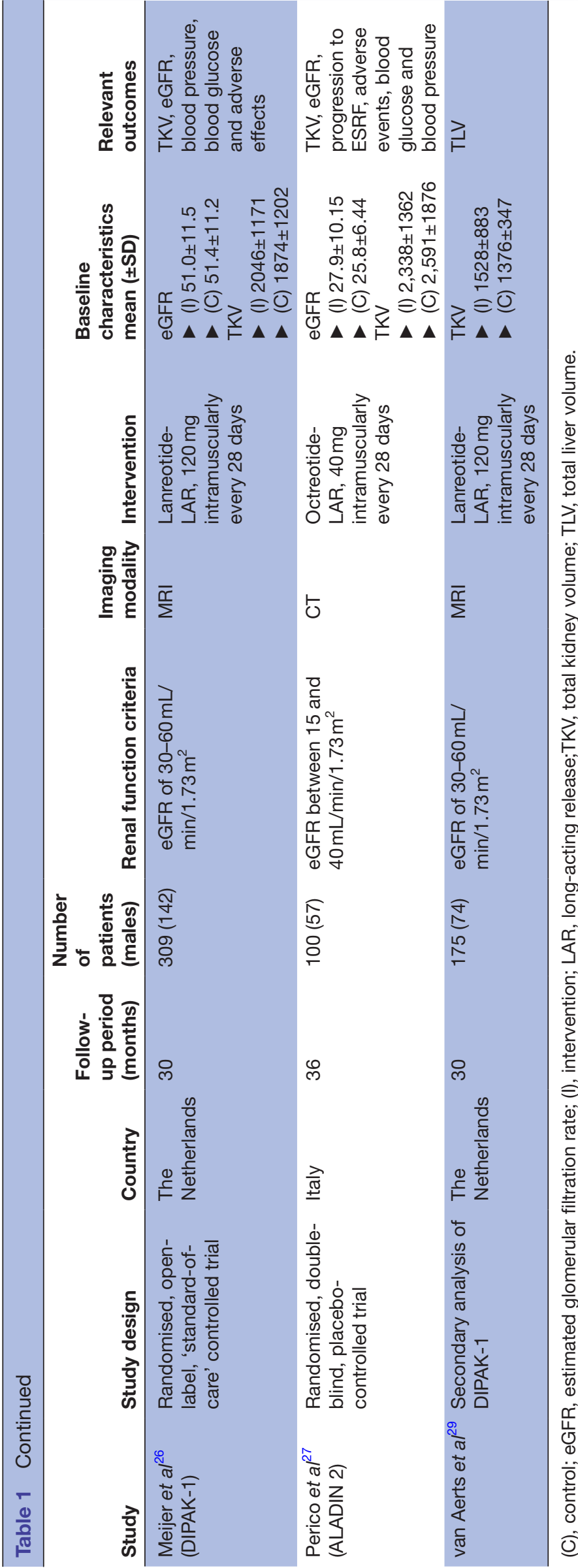




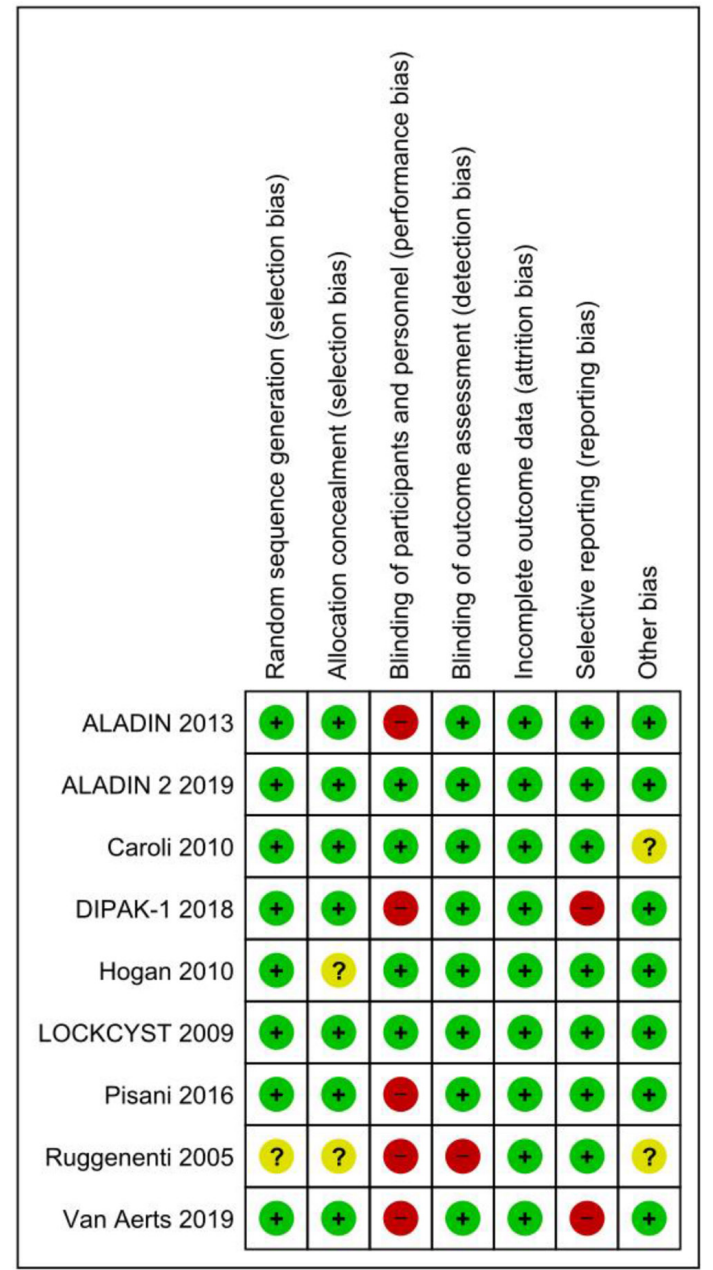

Figure 2 Bias risk assessment summary. Green symbols represent low risk, yellow unclear risk and red high risk.

personnel. DIPAK-1 and the subsequent secondary analysis by van Aerts $e t a l^{29}$ did not report final TKV and TLV (although they did report absolute and percentage changes and changes from baseline in TKV and TLV), resulting in a high risk of bias for selective reporting. Visual inspection of funnel plots did not reveal significant publication bias (online supplementary figure 1A-G).

\section{Primary outcomes}

\section{Effect of somatostatin analogues on EGFR}

Five studies reported the effects of somatostatin analogues on eGFR in 480 patients. There were no significant differences in eGFR decline for ADPKD patients treated with somatostatin analogues compared with placebo controls (mean difference $0.27 \mathrm{~mL} / \mathrm{min} / 1.73 \mathrm{~m}^{2}, 95 \%$ CI -2.03 to $2.57, \mathrm{p}$ value $=0.82, \mathrm{I}^{2}=0 \%$ ) (figure $3 \mathrm{~A}$ ). There was no apparent difference in efficacy between lanreotide (mean difference $-0.60 \mathrm{~L}, 95 \% \mathrm{CI}-3.65$ to 2.45 , $\mathrm{p}=0.9$, $\mathrm{I}^{2}=\mathrm{N} / \mathrm{A}$ ) and octreotide treatment (mean difference 0.16 L, $95 \%$ CI -3.32 to $3.65, p=0.93, I^{2}=0 \%$ ) on eGFR (online supplementary figure $2 \mathrm{~A}$ ).
Effect of somatostatin analogues on TKV and TLV

Across the 6 studies in 497 patients, somatostatin analogue treatment did not result in a significant reduction in TKV for ADPKD patients when compared with placebo controls (mean difference $-0.19 \mathrm{~L}, 95 \% \mathrm{CI}-0.50$ to 0.12 , $\mathrm{p}$ value $=0.23, \mathrm{I}^{2}=52 \%$ ) (figure 3B). The level of heterogeneity in the studies for this outcome was high $\left(\mathrm{I}^{2}>50 \%\right)$. Sensitivity analysis showed no significant change in the overall effect when any single study was excluded but did demonstrate that the ALADIN 2013 and Hogan et at ${ }^{23}$ studies were associated with the highest level of heterogeneity. This was likely the result of variation in baseline TKV between control and treatment groups. Due to the limited number of studies available (less than 10) however, a meta-regression to account for baseline TKV could not be performed. Therefore, a further analysis assessing the difference between pretreatment and post-treatment means was conducted. This analysis demonstrated a mean difference of $-124 \mathrm{~mL}\left(95 \% \mathrm{CI}-190\right.$ to 58.7 , $\mathrm{p}$ value $\left.=0.0002, \mathrm{I}^{2}=0 \%\right)$ in TKV for participants treated with somatostatin analogues compared with placebo-treated participants (online supplementary figure 3). TLV was lower in somatostatin analoguetreated participants compared with controls across the 5 studies which included 311 patients (mean difference -0.15 $\mathrm{L}, 95 \% \mathrm{CI}-0.26$ to $-0.03, \mathrm{p}=0.01, \mathrm{I}^{2}=0 \%$ ) (figure $3 \mathrm{C}$ ). When studies are separated by choice of somatostatin analogue agent, lanreotide (mean difference $-0.15 \mathrm{~L}, 95 \% \mathrm{CI}-0.21$ to $\left.-0.1, \mathrm{p}<0.00001, \mathrm{I}^{2}=0 \%\right)$ appeared to be of more benefit when compared with octreotide (mean difference $-0.28 \mathrm{~L}$, $95 \% \mathrm{CI}-0.91$ to $0.35, \mathrm{p}=0.38, \mathrm{I}^{2}=71 \%$ ) for TKV outcomes (online supplementary figure 2B). Furthermore, lanreotide (mean difference $-0.14 \mathrm{~L}, 95 \%$ CI -0.26 to -0.02 , $\mathrm{p}=0.02$, $\mathrm{I}^{2}=0 \%$ ) also demonstrated a significant reduction in TLV, a finding which was not observed in the octreotide subgroup (mean difference $-0.17 \mathrm{~L}, 95 \% \mathrm{CI}-0.46$ to $0.12, \mathrm{p}=0.25$, $\mathrm{I}^{2}=0 \%$ ) (online supplementary figure $2 \mathrm{C}$ ).

\section{Secondary outcomes}

Effect of somatostatin analogues on BP

Systolic and diastolic BP were reported in four studies. Compared with placebo, somatostatin treatment did not significantly alter systolic BP (mean difference $1.24 \mathrm{~mm}$ $\mathrm{Hg}, 95 \% \mathrm{CI}-0.83$ to 3.31 , $\mathrm{p}$ value $=0.24, \mathrm{I}^{2}=0 \%$ ) (online supplementary figure 4A) or diastolic BP (mean difference $0.47 \mathrm{~mm} \mathrm{Hg}, 95 \% \mathrm{CI}-0.97$ to 1.91 , $\mathrm{p}$ value $=0.52$, $\mathrm{I}^{2}=0 \%$ ) (online supplementary figure $4 \mathrm{~B}$ ).

\section{Adverse effects of somatostatin analogues}

Across 5 studies and a total of 500 patients, somatostatin analogue treatment resulted in a significant increase in blood glucose (standardised mean difference $0.48,95 \%$ CI 0.19 to 0.77 , $\mathrm{p}$ value $=0.001, \mathrm{I}^{2}=49 \%$ ) (figure $4 \mathrm{~A}$ ). Somatostatin analogues increased the risk of known side effects such as diarrhoea (RR 4.83, 95\% CI 2.26 to 10.34 , p value $<0.001$, $\mathrm{I}^{2}=70.9 \%$ ), abdominal pain (RR 2.86, 95\% CI 1.50 to 5.45 , $\mathrm{p}$ value $\left.=0.001, \mathrm{I}^{2}=63 \%\right)$, cholelithiasis and cholecystitis $(\mathrm{RR}$ $4.8,95 \%$ CI 1.22 to 18.81 , p value $=0.02, \mathrm{I}^{2}=0 \%$ ) and alopecia $\left(\mathrm{RR} 5.88,95 \% \mathrm{CI} 1.3\right.$ to $26.61, \mathrm{p}$ value $\left.=0.02, \mathrm{I}^{2}=0.0 \%\right)$ 
A eGFR

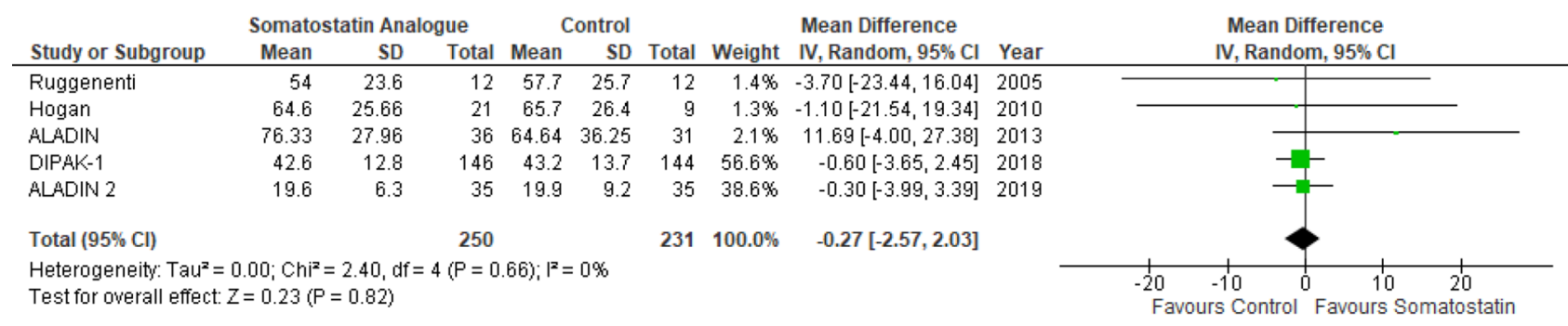

\section{B TKV}

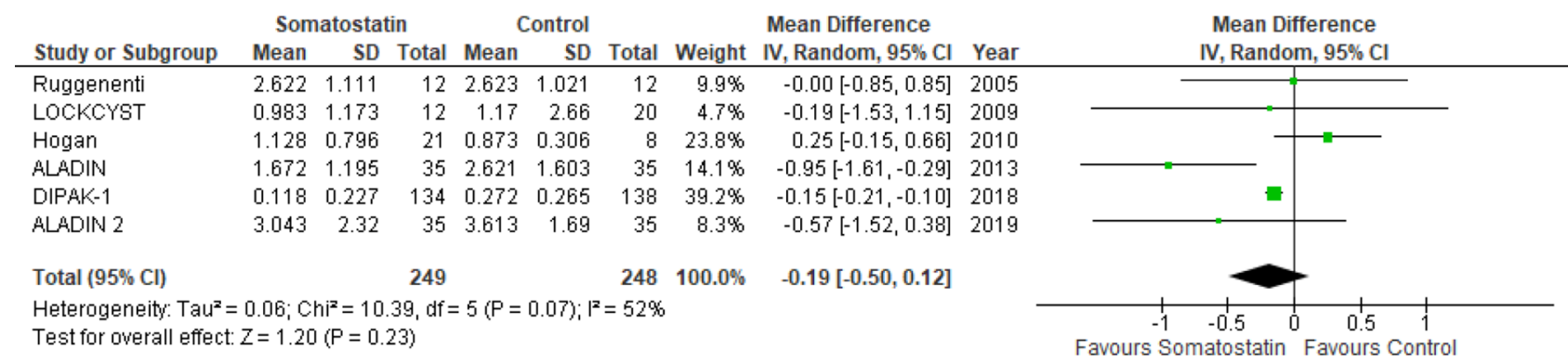

\section{TLV}

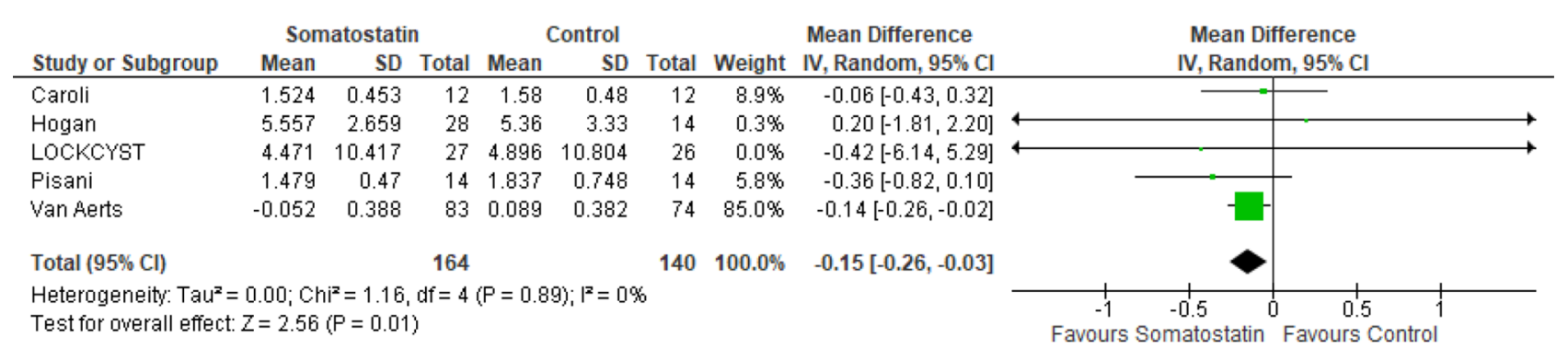

Figure 3 Primary outcomes. Somatostatin treatment has no effect on eGFR or TKV but reduces TLV. Forest plots depicting the effects of somatostatin analogue versus controls on eGFR (A), TKV (B) and TLV (C). Horizontal lines represent the $95 \%$ Cls. The studies with mean difference were indicated by coloured square. The diamond represented pooled mean difference analysis with a $95 \% \mathrm{Cl}$. eGFR,estimated glomerular filtration rate; TKV,total kidney volume; TLV, total liver volume.

(figure 4B-E). Furthermore, somatostatin analogue treatment was associated with an increased discontinuation rate (RR 2.64, 95\% CI 1.57 to 4.46 , p value $=0.0003$, $\mathrm{I}^{2}=35 \%$ ) compared with control groups (figure $4 \mathrm{~F}$ ). Given the moderate to high degree of heterogeneity in multiple outcomes, a sensitivity analysis was performed. However, there was no change to the overall effect for these outcomes with the exclusion of any single study.

Effect of somatostatin analogues on progression to ESRF or need for Renal Replacement Therapy (RRT)

Progression to RRT was reported only in two studies: DIPAK-1 and ALADIN 2. Across the 405 patients analysed, 6 patients treated with lanreotide and 10 from the placebo groups progressed to ESRF requiring RRT. Somatostatin treatment had no significant effect on the progression to ESRF (RR 0.64, 95\% CI 0.16 to 2.49, p value $=0.52$ ) (online supplementary figure 4C). There was a moderate level of heterogeneity associated with these results $\left(\mathrm{I}^{2}=39 \%\right)$.

\section{Effect of somatostatin analogues on mortality and rate of hospital admissions}

Mortality rates and rates of hospital admissions were not reported in any study.

\section{DISCUSSION}

To our knowledge, this is the first systematic review and meta-analysis of the clinical efficacy and safety of somatostatin analogues in ADPKD and PLD. The results of this analysis demonstrate that while treatment with somatostatin analogues in ADPKD and PLD results in reduced TLV, there was no improvement in eGFR or the rate of progression to ESRF requiring RRT. Our results also found no improvement in TKV with somatostatin 
A Blood Glucose

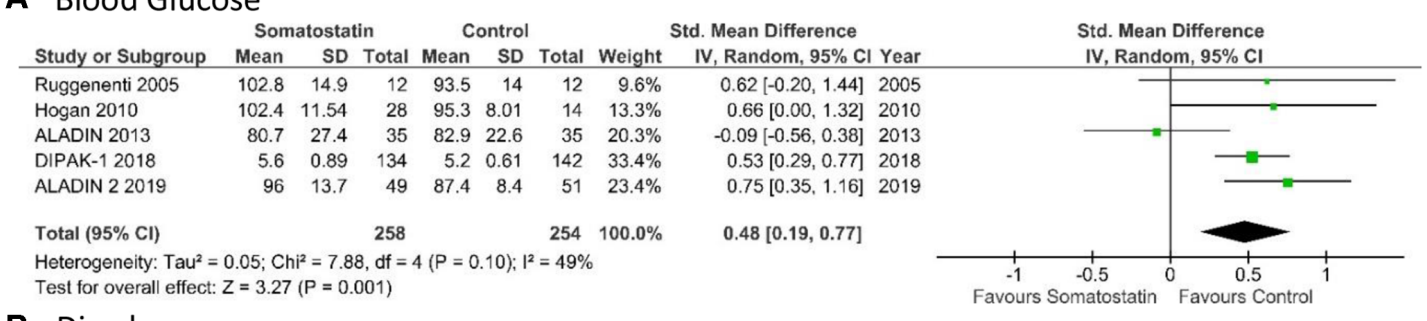

\section{B Diarrhoea}

\begin{tabular}{|c|c|c|c|c|c|c|c|c|c|c|c|}
\hline \multirow[b]{2}{*}{ Study or Subgroup } & \multicolumn{2}{|c|}{ Somatostatin } & \multicolumn{2}{|c|}{ Control } & \multirow[b]{2}{*}{ Weight } & \multicolumn{2}{|l|}{ Risk Ratio } & \multirow{2}{*}{\multicolumn{4}{|c|}{$\begin{array}{c}\text { Risk Ratio } \\
\text { M-H, Random, } 95 \% \text { Cl }\end{array}$}} \\
\hline & Events & Total & Events & Total & & $\mathrm{M}-\mathrm{H}$, Random, $95 \% \mathrm{Cl}$ & Year & & & & \\
\hline Ruggenenti 2005 & 3 & 6 & 0 & 6 & $5.8 \%$ & $7.00[0.44,111.91]$ & 2005 & & & & \\
\hline LOCKCYST 2009 & 19 & 27 & 3 & 27 & $16.8 \%$ & $6.33[2.12,18.92]$ & 2009 & & & & \\
\hline Hogan 2010 & 17 & 28 & 4 & 14 & $19.1 \%$ & $2.13[0.88,5.12]$ & 2010 & & & & \\
\hline ALADIN 2013 & 14 & 40 & 4 & 39 & $17.6 \%$ & $3.41[1.23,9.46]$ & 2013 & & & & \\
\hline DIPAK-1 2018 & 139 & 153 & 10 & 152 & $22.2 \%$ & $13.81[7.57,25.19]$ & 2018 & & & & - \\
\hline ALADIN 22019 & 15 & 49 & 5 & 51 & $18.5 \%$ & $3.12[1.23,7.94]$ & 2019 & & & & \\
\hline Total $(95 \% \mathrm{Cl})$ & & 303 & & 289 & $100.0 \%$ & $4.83[2.26,10.34]$ & & & & & \\
\hline Total events & 207 & & 26 & & & & & & & & \\
\hline Heterogeneity: $\mathrm{Tau}^{2}=$ & $.58 ; \mathrm{Chi}^{2}$ & 17.16, & $d f=5(P$ & $=0.00$ & 4); $I^{2}=71$ & & & 0.01 & 0.1 & 1 & 100 \\
\hline
\end{tabular}

\section{Abdominal Pain}

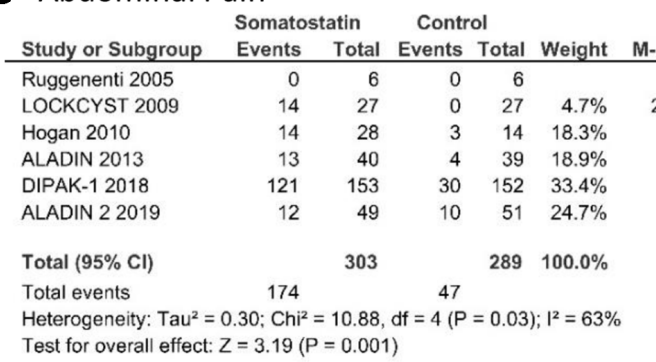

Risk Ratio

Risk Ratio

$\mathrm{H}$, Random, 95\% Cl Year Not estimable 2005 $29.00[1.82,462.85] 2009$ $2.33[0.80,6.80] 2010$ $3.17[1.13,8.88] 2013$ $4.01[2.88,5.58] 2018$ $1.25[0.59,2.62] 2019$

$2.86[1.50,5.45]$

Test for overall effect: $Z=3.19(P=0.001)$

D Cholelithiasis and cholecystitis

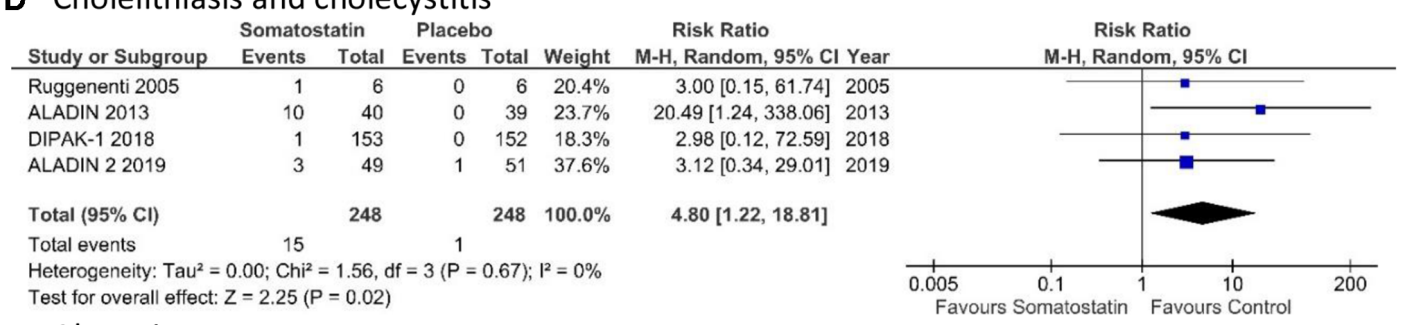

\section{E Alopecia}

\begin{tabular}{|c|c|c|c|c|c|c|c|c|c|c|}
\hline \multirow[b]{2}{*}{ Study or Subgroup } & \multicolumn{2}{|c|}{ Somatostatin } & \multicolumn{2}{|c|}{ Control } & \multicolumn{2}{|r|}{ Risk Ratio } & \multirow{2}{*}{\multicolumn{4}{|c|}{$\begin{array}{c}\text { Risk Ratio } \\
\mathrm{M}-\mathrm{H}, \text { Random, } 95 \% \mathrm{Cl}\end{array}$}} \\
\hline & Events & Total & Events & Total & Weight & M-H, Random, $95 \%$ Cl Year & & & & \\
\hline Hogan 2010 & 1 & 28 & 0 & 14 & $23.1 \%$ & $1.55[0.07,35.83] 2010$ & & & $=$ & \\
\hline ALADIN 2013 & 2 & 40 & 0 & 39 & $25.3 \%$ & $4.88[0.24,98.47] 2013$ & & & & \\
\hline DIPAK-1 2018 & 16 & 153 & 0 & 152 & $29.0 \%$ & $32.79[1.98,541.63] 2018$ & & & & $\stackrel{\longrightarrow}{\longrightarrow}$ \\
\hline ALADIN 22019 & 1 & 49 & 0 & 51 & $22.6 \%$ & $3.12[0.13,74.80] 2019$ & & & 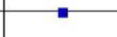 & \\
\hline Total $(95 \% \mathrm{Cl})$ & & 270 & & 256 & $100.0 \%$ & $5.88[1.30,26.61]$ & & & & \\
\hline Total events & 20 & & 0 & & & & & & & \\
\hline $\begin{array}{l}\text { Heterogeneity: } \mathrm{Tau}^{2}= \\
\text { Test for overall effect: }\end{array}$ & $\begin{array}{l}.00 ; \mathrm{Ch}^{2} \\
=2.30\end{array}$ & $\begin{array}{l}2.77, \mathrm{~d} \\
=0.02)\end{array}$ & if $=3(P=$ & 0.43 ); & $I^{2}=0 \%$ & & 0.01 & $\begin{array}{ll}0.1 & 1 \\
\text { s Somatostatin }\end{array}$ & 1 Favours Co & $\begin{array}{l}10 \\
\text { ontrol }\end{array}$ \\
\hline
\end{tabular}

\section{F Discontinuation Rates}

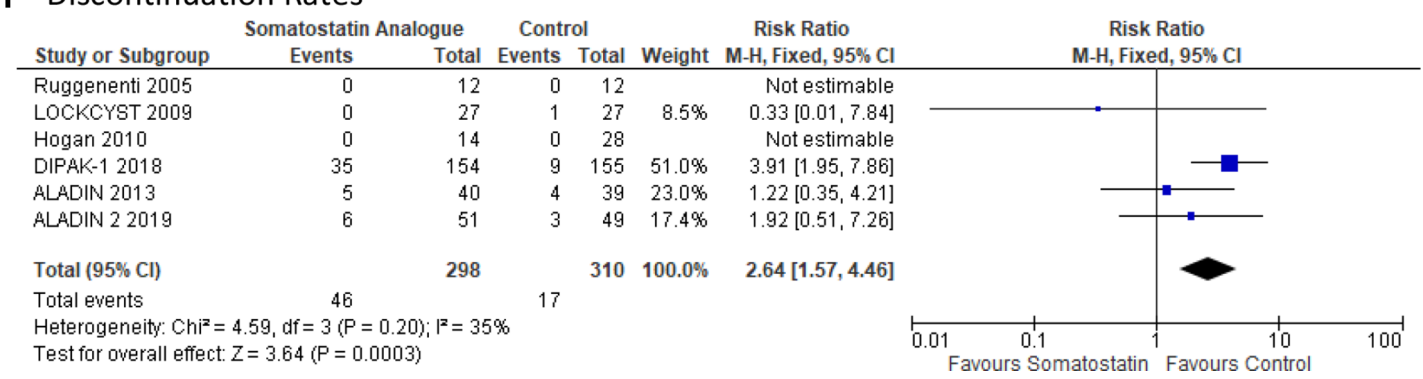

Figure 4 Adverse effects of somatostatin treatment. Forest plots depicting the effect of somatostatin analogue treatment versus control on blood glucose (A), diarrhoea (B), abdominal pain (C), cholelithiasis and cholecystitis (D), alopecia (E) and discontinuation rates (F). Treatment with somatostatin resulted in increased risk of all assessed adverse effects. Horizontal lines represent the $95 \% \mathrm{Cls}$. The studies with risk ratio or standardised mean difference were indicated by coloured square. The diamond represented pooled risk ratio or standardised mean difference analysis with a 95\% $\mathrm{Cl}$. 
analogue treatment. However, this was complicated by significant heterogeneity in these studies with differences in baseline TKV between control and treatment groups.

\section{Somatostatin analogue treatment reduces TKV but does not improve EGFR}

Although we were unable to use meta-regression, difference between means analysis suggests an improvement in TKV with somatostatin analogues. Our result is consistent with individual studies reporting a small reduction in the increase of TKV. In contrast, neither individual studies nor this meta-analysis demonstrated an effect on eGFR. TKV has been accepted as a prognostic biomarker by the US Food and Drug Agency (FDA) and European Medicines Agency (EMA) although its use as a surrogate disease or efficacy biomarker in patients with preserved renal function is still debated. ${ }^{32}$ The divergence between effects on TKV and eGFR is similar to that observed in previous clinical trials where a positive effect on TKV was associated with a neutral or negative effect on eGFR. ${ }^{2}$ The reasons for this difference are not clear but indicate that a change in TKV does not always equate to a benefit on renal function. Potentially, somatostatin analogues could themselves reduce GFR through haemodynamic changes although the effects reported so far in healthy controls and diabetic patients have been acute. ${ }^{33-35}$ Alternatively, the effects of somatostatin treatment on TKV may be too modest to translate into renal function improvement in a short clinical trial and more prolonged treatment period may be needed to demonstrate a measurable benefit on eGFR decline. However, this is likely to be offset by the downregulation of somatostatin receptors with prolonged exposure to somatostatin analogues, leading to reduced efficacy with long-term treatment. ${ }^{36}$ It should be noted that not all somatostatin analogues are identical with in vivo evidence that pasireotide is more effective than octreotide at inhibiting cyst development due to the broader range of somatostatin receptor subtypes it binds to and its longer half-life ${ }^{37}$ Pasireotide is currently being investigated in an RCT for PLD (NCT01670110) although not for ADPKD.

There was significant variation among the studies with regards to follow-up period with the shortest follow-up period being 3 months and the longest being 3 years. The landmark TEMPO trial demonstrated significant renoprotective effects after 3 years of treatment ${ }^{38}$ and therefore shorter treatment periods may fail to detect protective effects. Only the ALADIN and ALADIN 2 trials followed patients up for 3 years and therefore this metaanalysis may potentially miss important effects at long periods of treatment.

Progression to ESRF was only reported by DIPAK-1 and ALADIN 2 with 16 patients reaching this end point. The inclusion criteria of ALADIN 2 had a lower eGFR (15 and $40 \mathrm{~mL} / \mathrm{min} / 1.73 \mathrm{~m}^{2}$ ) than other studies and thus many patients who progressed to ESRF in the meta-analysis were from this study. ALADIN 2 alone showed a significant reduction in the progression to ESRF and all of those that progressed to ESRF had CKD4 (excluded from all other RCTs). This does raise the possibility of a potential role for somatostatin analogues in ADPKD patients with advanced CKD, although further investigation will be needed to confirm this observation.

\section{Somatostatin analogues reduce TLV}

In contrast to TKV, there was a clear effect of somatostatin analogues in this meta-analysis showing a significant reduction in TLV (figure 3C). The reasons behind this divergence are not clear. In ADPKD, women develop PLD more commonly than males and this is reflected in the larger number of female participants in trials where TLV was reported. Previous subgroup analysis of somatostatin analogues in PLD have demonstrated that women benefit more than men, ${ }^{17}$ and this may have exaggerated the benefits of treatment on TLV when compared with TKV where the gender difference has not been described.

Interestingly, several studies have commented that the benefits of somatostatin treatment may persist after treatment cessation. Indeed, Pisani et al reported that a residual volume reduction remained up to 5 years after treatment had ended and van Aerts et al reported TLV improvement throughout the 4-month washout period (long after the 28-day half-life of lanreotide). ${ }^{29}{ }^{30}$ These results suggest that somatostatin analogue treatment could confer a long-term benefit on TLV in patients with PLD. One serious concern surrounding tolvaptan treatment in ADPKD and PLD is the association with hepatotoxicity. Both the major tolvaptan ADPKD trials TEMPO $^{38}$ and REPRISE $^{39}$ ) demonstrated a significant risk of developing hepatotoxicity in 16 patients in the tolvaptan treatment group compared with 1 in the placebo group. The EMA have estimated a rare risk of severe hepatitis which may affect approximately 1 in 4000 ADPKD patients treated with tolvaptan. ${ }^{40}$

The association of hepatotoxicity with tolvaptan treatment may limit its use in PLD, therefore somatostatin analogues may prove a suitable alternative. It is, however, important to note that somatostatin analogue treatments have been associated with gall stone formation and cholecystitis $^{41}$ which was confirmed in our meta-analysis (figure 4D). This would have significance in patients with pre-existing liver disorders, including PLD. Careful safety analysis is likely to be required to assess the risks of somatostatin analogue and tolvaptan treatments in PLD. Screening for gallstones will likely be required before starting somatostatin analogue treatment in all PLD patients. In PLD, the treatment focus is not just on reducing TLV growth but also on improving symptoms and quality of life (QOL) measures. ${ }^{42}$ Patients with larger liver volumes report more frequent abdominal symptoms ${ }^{43}$ and increased TLV has been shown to correlate with patient reported QOL. ${ }^{44}$ Indeed, somatostatin analogues have been used off-label in severe PLD due to their effects on liver size and pooled analysis of two previous RCTs suggested that there was a benefit to patient reported QOL. ${ }^{45}$ While three trials did report 
QOL, different questionnaires were used: DIPAK-1 used a validated ADPKD questionnaire while LOCKCYST $^{24}$ and Hogan $e t a l^{23}$ used the SF-36 questionnaire, thus limiting the possibility of including QOL as a secondary outcome. An RCT investigating the effects of pasireotide-LAR on PLD (NCT01670110) may provide further evidence in this area using a PLD-specific QOL questionnaire. ${ }^{46}$

\section{Adverse effects of somatostatin analogue treatment}

The adverse effects of somatostatin treatment reported were generally what would be expected from the known side effects of somatostatin analogues. The most commonly reported adverse events were abdominal pain and diarrhoea which have been widely reported as relatively mild and resolving spontaneously. There were also significant increases in the incidence of more clinically important side effects such as cholelithiasis and cholecystitis, alopecia and increases in blood glucose. In the DIPAK-1 study, 7 of the 153 patients treated with lanreotide unexpectedly developed hepatic cyst infections. ${ }^{26}$ While all recovered from the acute episode with appropriate treatment, they required hospital admission and a prolonged course of antibiotic therapy of up to 90 days. Caution will be required when prescribing somatostatin analogues, particularly in patients with a history of hepatic cyst infections. Of interest, this complication was not observed in the ALADIN 2 study with the use of octreotide. $^{25}$

\section{CONCLUSIONS AND LIMITATIONS}

Our meta-analysis was limited by the small number of studies and patients included. In all, 9 papers were included, 3 of which were secondary analyses of previous studies with a total of 592 patients. Blinding bias risk was high in four of the larger RCTs, the largest being open label without the use of placebo (DIPAK-1) and another (ALADIN) being single-blinded thus exposing them to a high risk of blinding bias. There was a distinct lack of large-scale clinical data available, with the largest trial (DIPAK-1) contributing 300 patients. The studies included were all from European countries or the USA, with most patients being Caucasian. This limits the applicability of these results to other ethnic groups. There was also significant variation in choice of somatostatin analogue formulations between studies without a clear consensus emerging on the most appropriate agent. Our analysis suggests that lanreotide treatment may be of more benefit than octreotide with regards to TKV and TLV effects but the small number of studies will limit conclusions regarding optimal somatostatin agents at this point. The eGFR parameters for included patients varied significantly between trials, with some studies including participants only with CKD3/4 and others including those with normal renal function. We cannot exclude the possibility that somatostatin analogues could be beneficial to participants with more advanced kidney failure which this meta-analysis did not detect. No study reported hospital admissions or mortality rates, likely due to the low overall mortality and rate of hospital admissions in the combined cohort.

It should be noted that several studies reported differences in baseline TKV between treatment and control groups which risked confounding results from a metaanalysis using final post-treatment means. This was apparent given the high heterogeneity across the studies when reporting TKV. While exploratory analysis suggests that the change of TKV from baseline was improved with somatostatin treatment, this method of analysis is susceptible to bias. A meta-regression would normally be performed to account for the baseline differences although this is not recommended in meta-analyses with fewer than 10 studies. $^{20}$

Overall our results do not currently support a role for somatostatin analogues in slowing renal disease progression in ADPKD. There may be potential for a limited role in reducing liver cyst burden in patients with severe PLD and in patients with advanced CKD in limiting progression to ESRF, although confirmatory evidence from future trials is required.

Twitter Joshua Griffiths @DrJoshGriffiths, Mark T Mills @DrMarkMills and Albert CM Ong @Ong_Lab

Contributors $\mathrm{AO}$ conceived the idea. JG and MTM performed data extraction and bias assessments. JG performed data analysis and drafted the manuscript. AO revised intellectual content of the manuscript.

Funding The authors have not declared a specific grant for this research from any funding agency in the public, commercial or not-for-profit sectors. Publications charges were funded by the Sheffield Kidney Research Foundation.

Competing interests None declared.

Patient consent for publication Not required.

Provenance and peer review Not commissioned; externally peer reviewed.

Data availability statement Data are available upon reasonable request.

Open access This is an open access article distributed in accordance with the Creative Commons Attribution Non Commercial (CC BY-NC 4.0) license, which permits others to distribute, remix, adapt, build upon this work non-commercially, and license their derivative works on different terms, provided the original work is properly cited, appropriate credit is given, any changes made indicated, and the use is non-commercial. See: http://creativecommons.org/licenses/by-nc/4.0/.

\section{ORCID iDs}

Joshua Griffiths http://orcid.org/0000-0001-6429-8131

Albert CM Ong https://orcid.org/0000-0002-7211-5400

\section{REFERENCES}

1 Simms RJ. Autosomal dominant polycystic kidney disease. BMJ 2016;352:i679.

2 Ong ACM, Devuyst O, Knebelmann B, et al. Autosomal dominant polycystic kidney disease: the changing face of clinical management. Lancet 2015;385:1993-2002.

3 Willey CJ, Blais JD, Hall AK, et al. Prevalence of autosomal dominant polycystic kidney disease in the European Union. Nephrol Dial Transplant 2017;32:1356-63.

4 Luciano RL, Dahl NK. Extra-renal manifestations of autosomal dominant polycystic kidney disease (ADPKD): considerations for routine screening and management. Nephrol Dial Transplant 2014;29:247-54.

5 Porath B, Gainullin VG, Cornec-Le Gall E, et al. Mutations in GANAB, encoding the glucosidase ll $\alpha$ subunit, cause autosomaldominant polycystic kidney and liver disease. Am J Hum Genet 2016;98:1193-207. 
6 Mao Z, Chong J, Ong ACM. Autosomal dominant polycystic kidney disease: recent advances in clinical management. F1000Res 2016;5:2029.

7 van Aerts RMM, van de Laarschot LFM, Banales JM, et al. Clinical management of polycystic liver disease. J Hepatol 2018;68:827-37.

8 Cnossen WR, Drenth JPH. Polycystic liver disease: an overview of pathogenesis, clinical manifestations and management. Orphanet $J$ Rare Dis 2014;9:69.

9 Besse W, Dong K, Choi J, et al. Isolated polycystic liver disease genes define effectors of polycystin-1 function. J Clin Invest 2017; 127:1772-85.

10 Lee-Law PY, van de Laarschot LFM, Banales JM, et al. Genetics of polycystic liver diseases. Curr Opin Gastroenterol 2019;35:65-72.

11 Cornec-Le Gall E, Torres VE, Harris PC. Genetic complexity of autosomal dominant polycystic kidney and liver diseases. J Am Soc Nephrol 2018;29:13-23.

12 Ong ACM. Making sense of polycystic kidney disease. Lancet 2017;389:1780-2.

13 ACM O. Polycystic kidney disease: tolvaptan slows disease progression in late-stage ADPKD. Nat Rev Nephrol 2018.

14 Gansevoort RT, Arici M, Benzing T, et al. Recommendations for the use of tolvaptan in autosomal dominant polycystic kidney disease: a position statement on behalf of the ERA-EDTA working groups on inherited kidney disorders and European renal best practice. Nephrol Dial Transplant 2016;31:337-48.

15 Belibi FA, Reif G, Wallace DP, et al. Cyclic AMP promotes growth and secretion in human polycystic kidney epithelial cells. Kidney Int 2004;66:964-73.

16 Torres VE, Harris PC. Strategies targeting cAMP signaling in the treatment of polycystic kidney disease. JASN 2014;25:18-32.

17 Gevers TJG, Inthout J, Caroli A, et al. Young women with polycystic liver disease respond best to somatostatin analogues: a pooled analysis of individual patient data. Gastroenterology 2013;145:357-65.

18 Temmerman F, Gevers T, Ho TA, et al. Safety and efficacy of different lanreotide doses in the treatment of polycystic liver disease: pooled analysis of individual patient data. Aliment Pharmacol Ther 2013;38:397-406.

19 Liberati A, Altman DG, Tetzlaff J, et al. The PRISMA statement for reporting systematic reviews and meta-analyses of studies that evaluate health care interventions: explanation and elaboration. $J$ Clin Epidemiol 2009:62:e1-34.

20 Higgins J, Green S. Cochrane handbook for systematic reviews of interventions version 5.1.0. The cochrane collaboration, 2011. Available: http://handbook.cochrane.org [Accessed Mar 2011].

21 Review Manager (RevMan) [Computer program] [program]. Version 5.3. Copenhagen: The Nordic Cochrane Centre version 2014.

22 Higgins JPTet al. Measuring inconsistency in meta-analyses. BMJ 2003;327:557-60.

23 Hogan MC, Masyuk TV, Page LJ, et al. Randomized clinical trial of long-acting somatostatin for autosomal dominant polycystic kidney and liver disease. JASN 2010;21:1052-61.

24 van Keimpema L, Nevens F, Vanslembrouck R, et al. Lanreotide reduces the volume of polycystic liver: a randomized, double-blind, placebo-controlled trial. Gastroenterology 2009;137:1661-8.

25 Caroli A, Perico N, Perna A, et al. Effect of long acting somatostatin analogue on kidney and cyst growth in autosomal dominant polycystic kidney disease (ALADIN): a randomised, placebocontrolled, multicentre trial. The Lancet 2013;382:1485-95.

26 Meijer E, Visser FW, van Aerts RMM, et al. Effect of lanreotide on kidney function in patients with autosomal dominant polycystic kidney disease: the DIPAK 1 randomized clinical trial. JAMA 2018;320:2010-9.

27 Perico N, Ruggenenti P, Perna A, et al. Octreotide-LAR in laterstage autosomal dominant polycystic kidney disease (ALADIN 2): a randomized, double-blind, placebo-controlled, multicenter trial. PLoS Med 2019;16:e1002777.

28 Ruggenenti P, Remuzzi A, Ondei P, et al. Safety and efficacy of longacting somatostatin treatment in autosomal-dominant polycystic kidney disease. Kidney Int 2005;68:206-16.

29 van Aerts RMM, Kievit W, D'Agnolo HMA, et al. Lanreotide reduces liver growth in patients with autosomal dominant polycystic liver and kidney disease. Gastroenterology 2019;157:481-91.

30 Pisani A, Sabbatini M, Imbriaco M, et al. Long-term effects of octreotide on liver volume in patients with polycystic kidney and liver disease. Clin Gastroenterol Hepatol 2016;14:1022-30.

31 Caroli A, Antiga L, Cafaro M, et al. Reducing polycystic liver volume in ADPKD: effects of somatostatin analogue octreotide. CJASN 2010;5:783-9.

32 Perrone RD, Mouksassi M-S, Romero K, et al. Total kidney volume Is a prognostic biomarker of renal function decline and progression to end-stage renal disease in patients with autosomal dominant polycystic kidney disease. Kidney Int Rep 2017;2:442-50.

33 Brouhard BH, LaGrone LF, Richards GE, et al. Somatostatin limits rise in glomerular filtration rate after a protein meal. $J$ Pediatr 1987:110:729-34.

34 Vora J, Owens DR, Luzio S, et al. Renal response to intravenous somatostatin in insulin-dependent diabetic patients and normal subjects. J Clin Endocrinol Metab 1987;64:975-9.

35 Ginès $A$, Salmerón JM, Ginès $P$, et al. Effects of somatostatin on renal function in cirrhosis. Gastroenterology 1992;103:1868-74.

36 Casar-Borota O, Heck A, Schulz S, et al. Expression of SSTR2a, but not of SSTRs 1,3 , or 5 in somatotroph adenomas assessed by monoclonal antibodies was reduced by octreotide and correlated with the acute and long-term effects of octreotide. J Clin Endocrinol Metab 2013;98:E1730-9.

37 Masyuk TV, Radtke BN, Stroope AJ, et al. Pasireotide is more effective than octreotide in reducing hepatorenal cystogenesis in rodents with polycystic kidney and liver diseases. Hepatology 2013;58:409-21.

38 Torres VE, Chapman AB, Devuyst O, et al. Tolvaptan in patients with autosomal dominant polycystic kidney disease. N Engl J Med 2012;367:2407-18.

39 Torres VE, Chapman AB, Devuyst O, et al. Tolvaptan in later-stage autosomal dominant polycystic kidney disease. $N$ Engl J Med 2017;377:1930-42

40 Sans-Atxer L, Joly D. Tolvaptan in the treatment of autosomal dominant polycystic kidney disease: patient selection and special considerations. Int J Nephrol Renovasc Dis 2018;11:41-51.

41 Attanasio R, Mainolfi A, Grimaldi F, et al. Somatostatin analogs and gallstones: a retrospective survey on a large series of acromegalic patients. J Endocrinol Invest 2008;31:704-10.

42 van Keimpema L, Höckerstedt K. Treatment of polycystic liver disease. Br J Surg 2009;96:1379-80.

$43 \mathrm{Kim} \mathrm{H}$, Park HC, Ryu H, et al. Clinical correlates of mass effect in autosomal dominant polycystic kidney disease. PLoS One 2015; 10:e0144526.

44 Neijenhuis MK, Kievit W, Verheesen SM, et al. Impact of liver volume on polycystic liver disease-related symptoms and quality of life. United European Gastroenterol J 2018;6:81-8.

45 Neijenhuis MK, Gevers TJG, Nevens F, et al. Somatostatin analogues improve health-related quality of life in polycystic liver disease: a pooled analysis of two randomised, placebo-controlled trials. Aliment Pharmacol Ther 2015;42:591-8.

46 Neijenhuis MK, Gevers TJG, Hogan MC, et al. Development and validation of a disease-specific questionnaire to assess patientreported symptoms in polycystic liver disease. Hepatology 2016;64:151-60. 